\title{
Pharmacoeconomic Analysis of Alcohol-Dependent Patients Drug Therapy
}

\author{
Larisa B. Vaskova, Elena A. Maksimkina and Manuk A. Arabyan
}

Department of Pharmacoeconomics and Administration at the Sechenov

First Moscow State Medical University 19991, 8/2 Trubetskaya Str., Moscow, Russian Federation

(Received: June 19, 2018; Accepted: February 05, 2019; Published (Web): April 01, 2019)

\begin{abstract}
Methodologic approach to the pharmacoeconomic evaluation of the drug therapy for alcoholdependent patients in an inpatient facility in real clinical practice was proposed by the authors. The aim of the study was to perform a pharmacoeconomic analysis of the disease treatment cost in alcohol-dependent patients according to their primary diagnosis in an inpatient facility.During the period from 2015 to 2016, the authors analyzed 120 medical histories of patients with primary diagnosis F.10.2 (Alcohol dependence) - disease-related group (DRG) №1 and F.10.3 (Alcohol withdrawal syndrome) - DRG №2. In total, in 2015 there were 27 drugs from 15 PT groups indicated and in 2016 - 36 drugs from 16 PT groups. It was established that in 2015 the main budget share was spent on PTG antiepileptics and vitamins (68.14 USD or $21.24 \%$ and 59.23 USD or $18.46 \%$ of the total sun, respectively), and in 2016 - on PTG anxiolytics and antidepressants (99.41 USD or 16.67\%).
\end{abstract}

Key words: alcohol dependence, pharmacoeconomic studies, treatment cost analysis, withdrawal syndrome

\section{INTRODUCTION}

Alcohol abuse in Russia is not only a medical, but also social-economical problem. According to the data of Rospotrebnadzor, by 2015 the amount of Russians with alcohol related diseases exceeded $5,000,000$ people or $3.4 \%$ of the total population. The vast majority (90\%) of them are people of workingage from 20 to 59 years old. The experts of the World Health Organization (WHO) report that 2.5 million people, who abuse alcohol, untimely die annually worldwide, which is $4 \%$ of the total mortality rate. ${ }^{1,2}$

The rating of countries by the level of alcohol consumption, stated in liters of pure ethanol consumption per capita, was calculated by the methodical procedure of the WHO, a special institution of the United Nations Organization system, which main function is population health protection worldwide and handling of international

Correspondence to: Larisa B. Vaskova

E-mail:vaskovalb@mail.ru; Tel.: +7 (916) 222-30-17

Dhaka Univ. J. harm. Sci. 18(1): 39-42, 2019 (June) DOI: https://doi.org/10.3329/dujps.v18i1.41425 healthcare issues. ${ }^{3}$ According to the study conducted in 2014, the leading country in the rating of countries with the highest alcohol consumption rate (Table 1) was Moldova (18.22 liters of pure ethanol consumption per capita). However, Russia was also shown to be among the leaders (15.76 liters of pure ethanol consumption per capita). ${ }^{4}$

According to the Russian State Statistics Service data, in 2013 the summarized amount of the expenses on patients with alcohol related diseases was 9,7 billion USD, which was around $2 \%$ of the gross domestic product (GDP), at the same time, $4 \%$ of GDP was spent on healthcare service in total. ${ }^{1}$

Alcohol abuse leads to high level of mortality among 40-60 year old men, who possess most valuable professional skills. Their untimely deaths have negative impact on country labor resources of professional specialists and reduce the investments into human assets. ${ }^{5}$

According to the National security strategy of the Russian Federation until 2020, approved by the Decree of the President of the Russian Federation, 
dated May $12^{\text {th }}$ 2009, N 537, the stabilization of population size and improvement of demographical situation are strategic objectives to provide national safety, and alcohol abuse is defined as one of the main threats to the national safety in the sphere of healthcare. ${ }^{6}$

Table 1. The rating of countries worldwide by the level of alcohol consumption (liters per capita)

\begin{tabular}{llc}
\hline Place & Country & Consumption \\
\hline 1 & Moldova & 18.22 \\
2 & Czech Republic & 16.45 \\
3 & Hungary & 16.27 \\
4 & Russia & 15.76 \\
5 & Ukraine & 15.60 \\
6 & Estonia & 15.57 \\
7 & Andorra & 15.48 \\
8 & Romania & 15.30 \\
9 & Slovenia & 15.19 \\
10 & Belarus & 15.13 \\
11 & Croatia & 15.11 \\
12 & Latvia & 15.03 \\
13 & SouthKorea & 14.80 \\
14 & Portugal & 14.55 \\
15 & Ireland & 14.41 \\
\hline
\end{tabular}

Inpatient treatment of alcohol dependence is a long-term and expensive process. The treatment is indicated for each patient by a narcologist individually.

Increase of expenses on healthcare service, associated with the cost increase of modern medical technologies and increase of life expectancy, does not agree with the limited financial resources, what requires the improvement of alcohol-dependent patients drugs supply system. ${ }^{7,8}$

Pharmacoeconomic studies are of interest to the system of healthcare and the society due to the necessity to cut the healthcare service costs, to evaluate total cost of different treatment methods, preventive measures and diagnostics and to choose strategically rational medical procedures and approaches to budget management. ${ }^{9}$

Economic analysis is an important source of information that allows the consumers and medical facilities to make correct decisions. ${ }^{10}$ It is necessary to raise medical specialists awareness on the main methods of pharmacoeconomics, which will contribute to the budget costs cut and healthcare service quality improvement.

\section{MATERIALS AND METHODS}

The study was conducted on the site of the University Clinical Hospital No. 3 based at the Psychiatric Clinics named after S.S. Korsakov.

During the study period from 2015 to 2016, the authors analyzed 120 medical histories of patients with F10 primary diagnosis code according to ICD10 (Mental and behavioral disorders due to use of alcohol). Two diagnosis-related groups (DRG) were selected: F 10.2 - alcohol dependence (DRG №1) and F 10.3 - alcohol withdrawal syndrome (DRG №2). Pharmacoeconomic analysis of the "disease treatment cost", structural analysis and correlation-regression analyses were performed.

\section{RESULTS AND DISCUSSION}

The analysis of the socio-demographical structure of the studied patient population for the period from 2015 to 2016 showed that the studied disease is common among married men aged $41-50$, who have college or university degree and a full-time job. The analysis of the parameters, that characterized the patients by the treatment plan, showed that the number of patients that received budget funded treatment in 2015 slightly exceeded the number of patients that received paid medical care $(51.11 \%$ and $48.89 \%$, respectively). In 2016 the number of patients, who received budget funded treatment exceeded the number of patients that received paid medical care $(56 \%$ and $44 \%$ respectively). The analysis of hospitalization rate showed that in 2015 the rate of readmissions (77.78\%) was significantly higher than the rate of first time admissions (22.22\%). However, in 2016 the rate of readmissions $(65.33 \%)$ decreased in relation to the rate of first time admissions (34.67\%).

Average time of hospitalization in 2015 was equal to 12 days, and in 2016 to 15 days, which 
complied with the Decree of Ministry of Healthcare of the Russian Federation dated May $17^{\text {th }}$ 2016, N 299 "Approval of primary specialized medical and sanitary care standard for patients with psychoactive substances dependence syndrome". ${ }^{11}$ It was determined that all the indicated drugs are included into pharmacotherapeutic groups from "Federal clinical recommendations on diagnostics and treatment of dependence syndrome" ${ }^{\text {, }}$, i.e. detoxicative drugs, vitamins, anxiolytics and hypnotics, anticonvulsants, dehydrating drugs, hepatoprotectors, nootropics, etc. In total, in 2015 there were 27 drugs from 15 PT groups indicated and in 2016 - 36 drugs from 16 PT groups.

In 2015 sodium chloride $0.9 \%$ solution for infusions had the highest indication rate among detoxicative drugs. It was indicated to all the patients and its indication rate was $100 \%$. Among antipsychotic drugs, haloperidol had the highest indication rate $(36.36 \%)$ and tiapride had the lowest indication rate $(13.64 \%)$. Phenazepam had the highest indication rate among anxiolytics (55.56\%), and sibason (diazepam) had the lowest indication rate (44.44\%). Among vitamins milgamma (pyridoxine +thiamine + cyanocobalamine + lidocaine) had the highest indication rate $(41.76 \%)$ and folic acid had the lowest indication rate $(8.33 \%)$.

In 2016 sodium chloride $0.9 \%$ solution for infusions had the highest indication rate among detoxicative drugs (91\%), among antipsychotic drugs haloperidol (34.69\%) and chlorprothixene (26.53\%) had the highest indication rate, azaleptin (clozapine) (8.16\%) and sonapax (thioridazine) (6.12\%) had the lowest indication rate. Among anxiolytics, phenazepam (75\%) had the highest indication rate and grandaxin (tofisopam) (3.85\%) had the lowest indication rate. Among vitamins, milgamma (pyridoxine +thiamine + cyanocobalamine + lidocaine) had the highest indication rate $(61.54 \%)$ and vitamin B1 (thiamine) had the lowest indication rate $(7.69 \%)$.

In 2015 the main budget share was spent on antiepileptic drugs and vitamins (68.14 USD or $21.24 \%$ and 59.23 USD or $18.46 \%$ of the total, respectively). This can be explained by the fact that antiepileptics Depakine Enteric and Depakin Chrono were indicated to 31 patients and had high cost. Drugs for vitaminization were not indicated often, but they were expensive. In 2016 the main budget share was spent on anxiolytics and antidepressants (136.78 USD or $22.95 \%$ and 99.41 USD or $16.67 \%$ of the total, respectively). This is explained by high indication rate of these drugs and their high cost.

Additionally, the authors performed correlationregression analysis based on the data from 2015. Thus, the rank correlation coefficient was calculated to determine the correlation between the patients' age and pharmacotherapy cost, hospitalization time of alcohol-dependent patients and pharmacotherapy cost. The cost of pharmacotherapy course was calculated for patients with withdrawal syndrome and alcohol dependence for each DRG. After that, the values were ranked and the rank correlation coefficient was calculated. It was determined that patient age factor moderately influenced on inpatient facility costs, because the correlation between patients age and pharmacotherapy cost in DRG №1 and DRG No. 2 was equal to $p=0.55$ and $p=0.6$, respectively. Significant correlation was identified between hospitalization time and pharmacotherapy cost for both DRGs ( $p=0.79$ for DRG No.1 and $\mathrm{p}=0.81$ for DRG No. 2), i.e. hospitalization time factor significantly influenced on inpatient facility costs. Low correlation was identified between disease duration and pharmacotherapy costs in DRG №1 ( $p=$ $0.46)$, this correlation was moderate in DRG №2 $(\mathrm{p}=$ $0.57)$.

\section{CONCLUSION}

The study of alcohol-dependent population structure in 2015-2016 showed that married men aged 41-50 with college or university degree and fulltime employment were most prone to the studied disease. The number of patients, who received budget funded treatment, exceeded the number of patients, who received paid medical care. Readmission rate was higher than the first time admission rate. Average hospitalization time was 12 days in 2015 
and 15 days in 2016, which complied with the Decrees of the Ministry of Healthcare of the Russian Federation.

The analysis of the indicated drugs range showed that the detoxicative drugs, antiepileptic drugs, Potassium and Magnesium containing drugs had the highest indication rate. Diuretics, bronchodilators and calcium channel antagonists had the lowest indication rate.

It was determined that in 2015 the main budget share was spent on antiepileptic drugs (21.24\%) and vitamins (18.46\%), in 2016 - on anxiolytics $(22.95 \%)$ and antidepressants (16.67\%).

\section{REFERENCES}

1. Malin, D.I. and Nedvedev, V.M. 2013. Clinical narcology. Vuzovskayakniga, Moscow.

2. Ivanets, N.N., Anokhina, I.P. and Vinnikova, M.A. 2008. Narcology: national guidelines. GEOTAR-media, Moscow.

3. WHO (The World Health Organization). 2017. Strategy on alcohol abuse reduction. Access request: http://www.who.int (date of request 12.12.2017).

4. Countries rating worldwide of the alcohol consumption per capita, the WHO revision. Access request:http://gtmarket.ru.

5. Bokhan, N.A. 2007. Lethality in alcohol dependent patients. Narcology 12, 37-40.

6. Portnov,A.A. and Pyatnitskaya, I.N. 2012. Alcoholic dependence (guidelines for doctors). Megapolis, Moscow.

7. Rosstat. 2016. Statistical data on Russia. Official publication. Rosstat, Moscow.

8. Decree of the Government of the Russian Federation dated December $30^{\text {th }} \quad 2009$, N 2128-pAccess request: http://www.fsrar.ru/policy_of_sobriety/koncepcia.

9. ICD-10 Version: 2016. Access request:http://apps.who.int/en (date of request 22.12.2017).

10. Sacks, J.J., Gonzales, K.R., Bouchery, E.E., Tomedi, L.E. and Brewer, R.D. 2015. National and state costs of excessive alcohol consumption. Am. J. Prev. Med. 49, 73-9.
11. Ministry of healthcare of the Russian Federation: Decree dated May $17^{\text {th }} 2016$ N 299n "Approval of primary specialized medical and sanitary care standard for patients with psychoactive substances dependence syndrome".

12. Federal clinical recommendations on diagnostics and treatment of alcohol dependence syndrome. July 2014.

13. Gofman, A.G., Orlova, M.A. and Meliksetyan, A.S. 2010. Soc. Clin. Psychiatry. 7-8.

14. Classification of nervous system disorders. 1994. 10th revision (ICD-10). ADIS., Saint Petersburg.

15. Nemtsov, A.V. and Terekhin, A.T. 2007. Alcohol related mortality rate and diagnostic structure in Russia. Narcology .12, 29-36.

16. Shabanov, P.D. 2003. Narcology: Practical guidance for doctors. GEOTAR-MED, Moscow.

17. ICD 10 - International Classification of Diseases 10th revision. Access request: http://mkb-10.com (date of request: 21.12.2017).

18. Federal Supervision Agency for Customer Protection and Human Welfare. Access request: http://rospotrebnadzor.ru (date of request 25.12.2017).

19. LEVADA-Center. Access request: http://www.levada.ru (date of request 15.12.2017).

20. Alcohol consumption per capita. Access request: http://vsezavisimosti.ru (date of request 23.12.2017).

21. Federal portal of normative acts projects. Access request: http://regulation.gov.ru (date of request 25.12.2017).

22. Official website of the Ministry of Healthcare of the Russian Federation. Access request: http://www.rosminzdrav.ru (date of request 06.03.2018).

23. Pharmacoeconomics. Access request: http://www. ecopharmacia.ru (date of request: 15.12.2017).

24. Ivanets, N.N., Anokhina, M.A. and Vinnikova, M.A. 2008. Narcology: National guidelines. GEOTARG-media, Moscow.

25. Rehm, J., Taylor, B. and Patra, J. 2006. Volume of alcohol consumption, patterns of drinking and burden of disease in the European region. Addiction. 101, 1086-1095.

26. Rehm, J. et al. 2003. The global distribution of average volume of alcohol consumption and patterns of drinking. Eur. Addict. Res. 9, 147-156. 